\title{
Detection of Degradation Effects in Field-Aged c-Si Solar Cells through IR Thermography and Digital Image Processing
}

\author{
E. Kaplani \\ Mechanical Engineering Department, T.E.I. of Patras, Megalou Alexandrou 1, 26334 Patra, Greece \\ Correspondence should be addressed to E. Kaplani, ekaplani@teipat.gr
}

Received 27 December 2011; Accepted 7 February 2012

Academic Editor: Peter Rupnowski

Copyright ( 2012 E. Kaplani. This is an open access article distributed under the Creative Commons Attribution License, which permits unrestricted use, distribution, and reproduction in any medium, provided the original work is properly cited.

Due to the vast expansion of photovoltaic (PV) module production nowadays, a great interest is shown in factors affecting PV performance and efficiency under real conditions. Particular attention is being given to degradation effects of PV cells and modules, which during the last decade are seen to be responsible for significant power losses observed in PV systems. This paper presents and analyses degradation effects observed in severely EVA discoloured PV cells from field-aged modules operating already for 1822 years. Temperature degradation effects are identified through IR thermography in bus bars, contact solder bonds, blisters, hot spots, and hot areas. $I-V$ curve analysis results showed an agreement between the source of electrical performance degradation and the degradation effects in the defected cell identified by the IR thermography. Finally, an algorithm was developed to automatically detect EVA discoloration in PV cells through processing of the digital image alone in a way closely imitating human perception of color. This nondestructive and noncostly solution could be applied in the detection of EVA discoloration in existing PV installations and the automatic monitoring and remote inspection of PV systems.

\section{Introduction}

During the last decade, the integration of photovoltaics (PV) in buildings, telecommunication stations, power plants, and industrial applications has greatly expanded, in an effort to provide cheaper and greener energy production and energy saving. While the $\mathrm{c}-\mathrm{Si}$ and $\mathrm{pc}-\mathrm{Si} \mathrm{PV}$ module production account together for about $83 \%$ of the market share worldwide [1], newer cell technologies such as thin film, a-Si, $\mathrm{CdTe}$, and $\mathrm{CuInSe}_{2}$ [2] are constantly being sought and further investigated in an attempt to provide higher module efficiency and more reliable PV performance. Recent research interest has shifted towards a deeper understanding of factors which affect PV performance and efficiency under real conditions, whereby the PV power output is often largely different from the expected performance under the specified factory rating norms. Temperature, solar irradiance, and spectral effects [3], as well as the degradation of PV cells and modules [4], which often appears after a few years of operation and continues to increase thereafter, are the main factors which attribute to the discrepancy observed. The extent of cell and module natural degradation after 20-25 years performance in silicon module productions can nowadays be observed [5].
Due to the complex manner in which these defects appear and interrelate, a deeper understanding of the nature of these defects and the degree to which they correlate with reduction in PV performance and efficiency is of prime importance both for the early and accurate defect detection in existing technologies and the offering of highly improved PV systems.

PV cell and module degradation has been attributed to the discoloration of the ethylene vinyl acetate (EVA) encapsulant used in PV modules, which is more evident in modules operating at locations of high ambient temperature and high solar irradiation especially at lower UV wavelengths [6]. Studies have reported on the degradation mechanisms of the EVA copolymer induced from UV and high temperatures developed in cells, involving the formation of acetic acid and polyenes, the production of ketone and aldehyde, and the production of acetaldehyde and other gases $[4,6]$. EVA discoloration is connected to the formation of polyenes and $\alpha, \beta$-unsaturated carbonyl products and, further, to the depletion in the UV stabilizing additives, such as Cyasorb UV 531 and Tinuvin $770[4,6]$. EVA discoloration in silicon PV cells appears in several degrees and extends from yellow to dark brown. Cell and module degradation is also attributed to the delamination of the encapsulant near the edges of 
the cell due to water penetration [7], the formation of high conductivity paths, known as shunts, inside the cell or along its edges as a result of crystal defects and impurities [8], and sometimes to manufacturing microdefects that may be passed through the fabrication process. Furthermore, external factors responsible for cell and module degradation include partial shading, dirt, or dust, which cause cell mismatch and may lead to the formation of hot spots and hot areas [9], or other factors such as cracks or sealant diffusion allowing humidity penetration [7].

Several of these factors are seen to cause a temperature increase at the defected area, which is often several degrees above the temperature of the healthy part of the cell. Depending on the severity of the defect and the extent of the cell area it covers, the temperature increase may be realized through hot spots or large hot areas. The defected cells are shown to produce less current, leading to cell mismatch in the module and result in the defected cell operating under reverse-bias mode, dissipating power in the form of heat [9]. Studies have shown that short-circuit current $\left(I_{\mathrm{sc}}\right)$ and fill factor $(\mathrm{FF})$ are significantly affected by module aging and cell degradation, leading to considerable maximum power $\left(P_{m}\right)$ losses, with FF decrease mainly attributed to degradation in the cell interconnections causing increase in the series resistance $\left(R_{s}\right)$, and $I_{\mathrm{sc}}$ losses mainly due to degradation in the optical properties (EVA discoloration, delamination, etc.) [10]. Furthermore, nonuniform EVA degradation among modules leads to additional power losses due to mismatch [6].

Optical defects including EVA discoloration, delamination, cracks, and humidity ingress along with corrosion defects in the metallic elements of the cell can be easily detected by means of visual inspection. Recently, great interest is shown in the use of IR thermography for nondestructive testing and inspection of PV modules. As defected cell areas exhibit higher or lower localized temperature than that of the remaining cell, the use of an IR camera to capture the temperature distribution on the surface of the cell can easily assist in the detection of these defects. Recent studies have reported on the detection of hot spots and hot areas using conventional IR cameras [11, 12]. The use of IR cameras equipped with spectral filters with IR sensitivity in the midwavelength rather than the conventional long-wave IR detectors was shown to effectively aid in the identification of shunt paths and resistive solder bonds in solar cells [13].

The study presented in this paper analyses aging defects appearing in 18-22-year-old PV modules, identified by means of IR thermography and digital image processing. The defects detected show the extent of optical degradation after several years of module operation in field conditions. $I-V$ curves obtained from these PV modules assisted in the determination of the degree of performance degradation and verified the results of IR and digital image processing attributing the source of power and current losses to degradation in the cell interconnections and its optical properties.

\section{Experimental Methodology}

Experiments were performed during a period of several months on SIEMENS M55 and BP B 1233 c-Si PV modules with 18 and 22 years of field operation, respectively, at the R.E.S. Lab of T.E.I. of Patras, Greece. Both digital images and IR images were obtained from cells exhibiting different degrees and forms of optical degradation. Images of the cell neighborhood were also obtained for relative comparison reasons.

Digital images were obtained using a conventional 7.1 MP digital camera. The digital images were processed and analysed with software developed for the purposes of this study in MATLAB environment. The IR images were obtained using TROTEC IC080LV thermocamera with detector resolution $384 \times 288$ pixels and accuracy of $\pm 2^{\circ} \mathrm{C}$. The detector is an uncooled microbolometer with spectral range 7.5 to $14 \mu \mathrm{m}$. For the calibration settings, emissivity was set to 0.83 for the front glass side of the cell and 0.91 for the back side Tedlar surface. The temperature data files extracted using the specialized camera software were then processed and analysed in MATLAB. For the $I-V$ curves obtained, an $I-V$ curve analyser for photovoltaics, PV-KLA, was used with a silicon irradiance sensor Si-01TCext with active temperature compensation and a PT-100 sensor for measuring module temperature. For each measurement the temperature coefficients of $P_{m}, I_{\mathrm{sc}}$, and $V_{\mathrm{oc}}$ for the PV module were set.

The experiments with the SIEMENS M55 modules were performed during September 2011 on days 13, 17, and 27, while the experiment with the BP B 1233 PV module was performed during April 2011 on day 8. At the time of the experiment, the following parameters were recorded: the ambient temperature via means of an MP101A sensor, the wind speed via means of a 05103 R.M. Young wind sensor and the global solar radiation at horizontal via means of a CM6B pyranometer.

\section{Visual Inspection}

Several SIEMENS M55 PV panels operating for 18 years in the T.E.I. of Patras, Greece, were visually examined for signs of optical degradation. The panels have been exposed to the rather hot and dry Greek climate, and about 10 years ago lumps of mortar were incidentally shed on the PV array and covered several cells for a prolonged period of several months (see Figure 1).

Although EVA discoloration in panels is known to be heterogeneous, the fact that some cells exhibit a significantly higher degree of browning is highly considered to be because of the shading effect caused by the layer of mortar. This induced shading effect caused the cells covered by this layer of mortar to operate under reverse bias mode, developing higher temperatures within the cell due to Joule effect. These modules exhibit now different types of degradation effects and to a different degree. These include browning due to EVA discoloration, corrosion of contacts and fingers, delamination, and humidity ingress, see Figure 2.

\section{IR Thermography}

4.1. Junction Box Effects. The IR images of the SIEMENS M55 modules were obtained using the thermocamera. The 


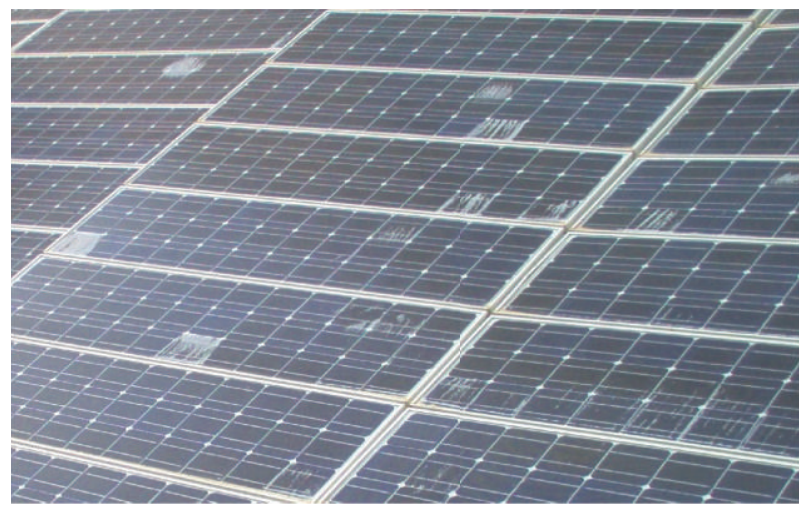

FIgURE 1: SIEMENS M55 PV generator subjected to lumps of mortar during the past.

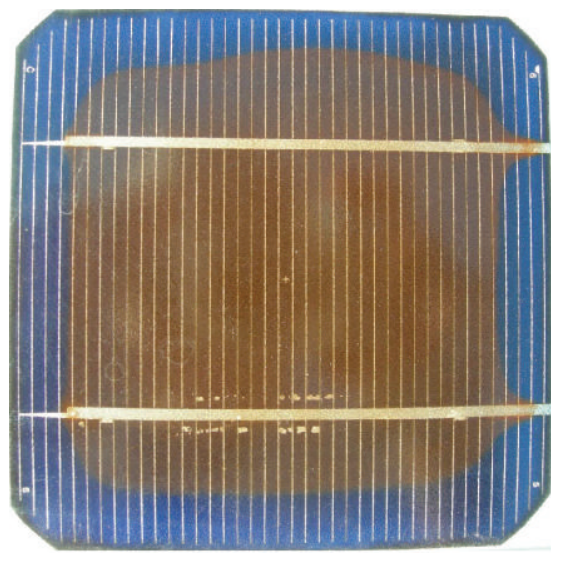

(a)

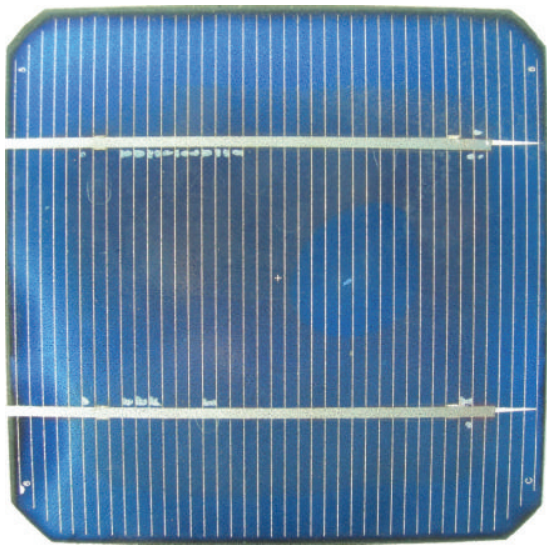

(b)

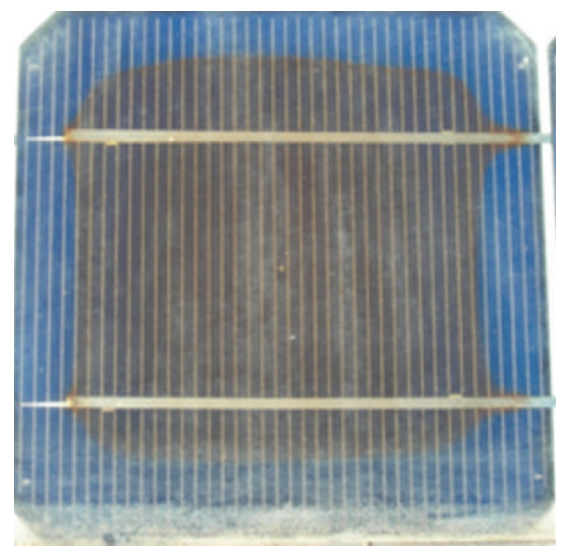

(c)

FIGURE 2: Various degradation effects observed in 18-year-old SIEMENS M55 PV cells.

ambient temperature recorded was $31.5^{\circ} \mathrm{C}$, the average wind speed was $2 \mathrm{~m} / \mathrm{sec}$, and the global solar radiation at horizontal was $680.5 \mathrm{~W} / \mathrm{m}^{2}$.

IR thermography shows the temperature distribution on the PV surface. When taken from a distance only large temperature variations can be observed. Figure 3 shows the front and back of two PV modules. A hot spot area with an increased temperature of about $7^{\circ} \mathrm{C}$ compared to the temperature of the rest of the module is shown at the cell where the bypass diode box lies. The IR image of the back of the modules shows an even higher temperature at the sealant of the junction box. This temperature increase at the cell where the junction box lies causes a difference in voltage $\delta V_{\mathrm{oc}}$, resulting in mismatch between the cells equivalent to partial shadowing effects and leads to a $\delta P_{m}$ reduction in the power output. As this effect is constant, the cell operating under increased temperature will eventually experience a slow physical degradation leading to permanently reduced power output.

Furthermore, cell temperatures measured at the back of the panel are observed to be higher by about $7-10^{\circ} \mathrm{C}$ from temperatures measured at the front. This is due to the increase of the thermal resistance added by the tedlar insulation at the back of the module. Based on the heat conduction law, the temperature at the back due to higher insulation is expected to be higher than temperatures at the front of the panel.

4.2. Browning and Bus Bar Degradation Effects. The IR images of cells exhibiting different degree of browning were captured for the determination of any temperature degradation effects. Figures 4(a) and 4(b) show the digital image and the IR image of a c-Si cell neighborhood from a SIEMENS M55 panel, whereby the bottom corner cell with severe EVA discoloration is shown in the IR image to display an average temperature increase by about $25^{\circ} \mathrm{C}$ compared to the temperature of the nearby cells exhibiting browning to a lesser degree. Furthermore, the IR image reveals the existence of two hot spots reaching $86^{\circ} \mathrm{C}$, a relative increase by more than $35^{\circ} \mathrm{C}$ with respect to the temperature of the nearby cells. Due to the overall conductance of the PV module front cover, heat propagates around the hot spots, while the tedlar insulation at the back of the panel having low conductivity discloses the hot spots more clearly. The IR image at the back side tedlar surface of the cell reveals that these two hot spots are located on the bus bars of the cell, see Figure 5(b). The larger one appears at the soldering bond where the contact is corroded (see Figure 4(a)). The temperature of these hot spots at the back side of the cell reaches $96^{\circ} \mathrm{C}$, 


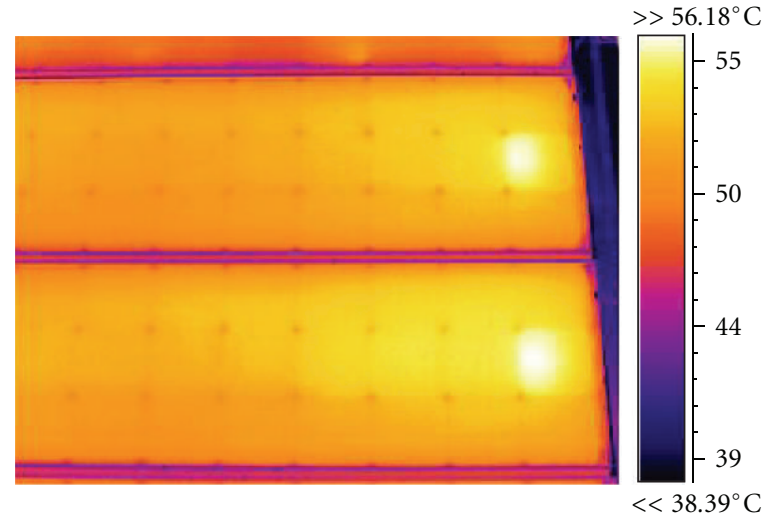

(a)

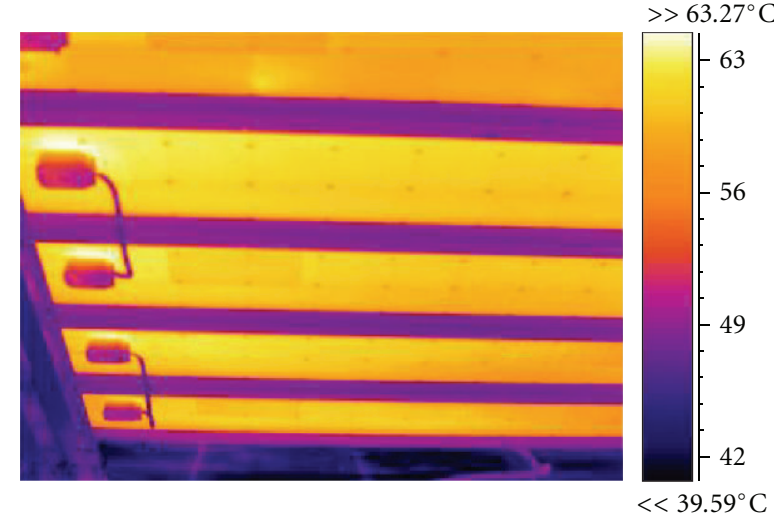

(b)

FIGURE 3: IR image of PV modules showing hot area at the junction box, (a) at the front of the panels, and (b) at the back of the panels.

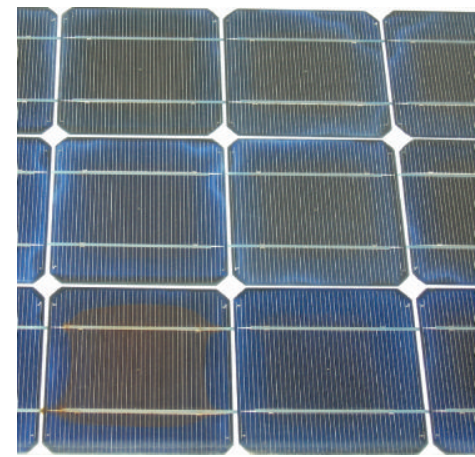

(a)

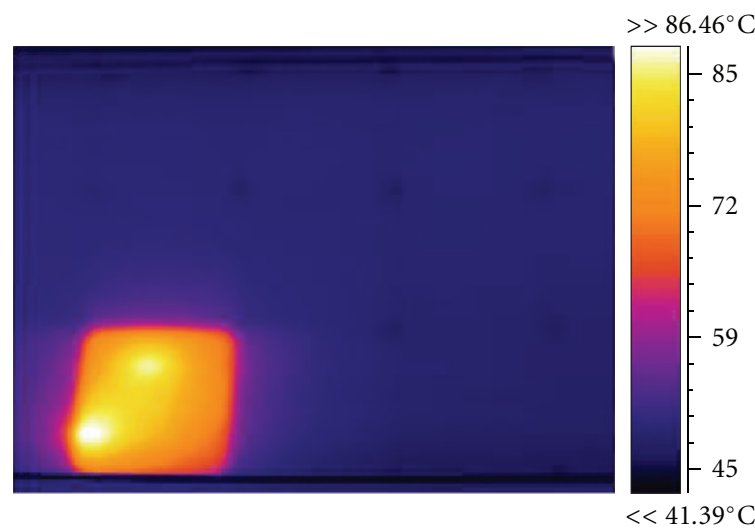

(b)

FIGURE 4: (a) Digital and (b) IR image, of browned cell and neighboring cells. IR image reveals two hot spots at the severely browned cell.

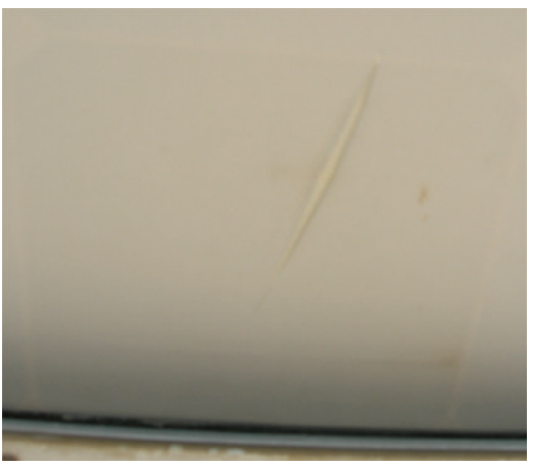

(a)

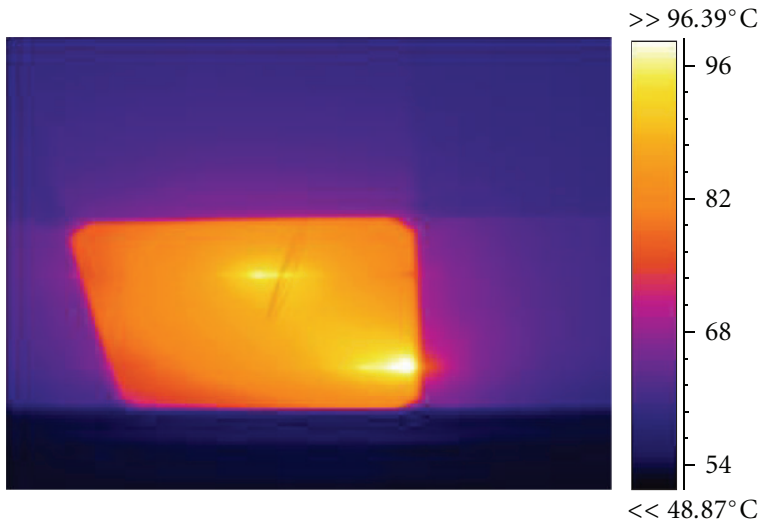

(b)

Figure 5: (a) Digital and (b) IR image, of the back of the severely browned cell of Figure 4. IR images reveals the two hot spots are located on the two bus bars. The tear of the tedlar sheet also appears in the IR image. 


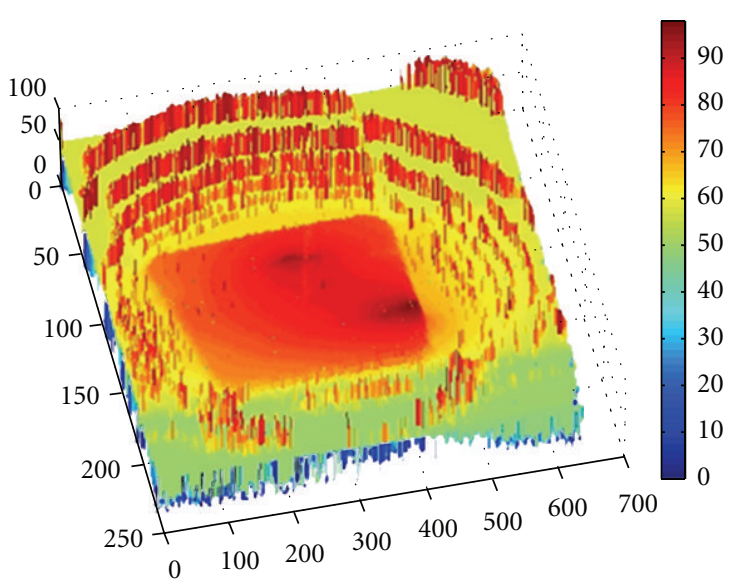

FIGURE 6: 3D temperature plot of IR data extracted from the back of the cell of Figure 5(b).

which is detrimental to the operational lifetime of the cell. At the time of the experiment, the ambient temperature was $32.2^{\circ} \mathrm{C}$, the wind speed was $2.2 \mathrm{~m} / \mathrm{sec}$, and the global solar radiation at horizontal was $607.1 \mathrm{~W} / \mathrm{m}^{2}$. During summer higher temperatures have been recorded, with the hot spot reaching temperatures above $100^{\circ} \mathrm{C}$.

Figure 5(a) also shows a tear in the tedlar sheet, which also appears in the IR image crossing through the bus bar at the hot spot and displaying slightly lower temperature at the edges of the tear (see Figure 5(b)). The temperature data extracted from the back side of the cell of Figure 5(b) were also analysed in MATLAB. The data were filtered with a $3 \times 3$ median filter. The 3D temperature plot is shown in Figure 6 . The two hot spots appear clearly and the small temperature decrease at the place of the tear is now obvious. A temperature pattern appears, due to heat propagation, between the two hot spots which replicates the exact temperature pattern observed at the front side of the cell.

4.3. Blister Effects. Another SIEMENS M55 c-Si cell exhibiting severe browning discoloration, particularly evident at the bus bar contacts and solder bond, is displayed in Figure 7(a). The image of the back of the cell (Figure 7(b)) exhibits a large blister at the bottom bus bar and a smaller blister at the top bus bar. The browning at the bus bar and solder bond is also visible at the back of the cell. The IR image at the front and back side of the cell are displayed in Figures $8(\mathrm{a})$ and $8(\mathrm{~b})$, respectively. The ambient temperature recorded was $36.5^{\circ} \mathrm{C}$, the wind speed was $1.7 \mathrm{~m} / \mathrm{sec}$, and the global solar radiation at horizontal was $717.1 \mathrm{~W} / \mathrm{m}^{2}$.

A large hot spot area is visible in the front IR image, while the IR image at the back displays more information. A hot spot appears on the bus bar with its temperature reaching nearly $99^{\circ} \mathrm{C}$, extremely detrimental for the operational health of the cell, which is higher by about $30^{\circ} \mathrm{C}$ from the remaining part of the cell. An extended part of the bus bar around the hot spot appears with also an increased temperature by $15-$ $25^{\circ} \mathrm{C}$ compared to the temperature of the remaining part of the cell. An effect of this extreme temperature of the bus bar is a blister which has formed at the tedlar backsheet cover located on the bus bar at the edges of this hot area. The blister exhibits lower temperature $63^{\circ} \mathrm{C}$, about $6-7^{\circ} \mathrm{C}$ below the temperature of the remaining part of the cell.

4.4. Natural Discoloration, Hot Spots and Hot Areas. A 22year-old c-Si BP B 1233 PV module examined revealed natural EVA discoloration on all of its cells covering about $90 \%$ of the cell area. The EVA discoloration appears not only on the surface of the cell but also on the street surface between the cells. The digital image of the lower part of the panel is displayed in Figure 9(a). The IR image of the back of the panel reveals one of the cells to exhibit higher temperature than the others (see Figure 9(b)).

The temperature data extracted from the back of the panel were further analysed in MATLAB, and the 3D temperature plot is displayed in Figure 10(a). A temperature pattern with a hot area reaching $53^{\circ} \mathrm{C}$ appears on the cell indicated by the arrow. Temperature data extracted from the IR images capturing this cell from the front glass side are plotted in Figure 10(b) together with neighbouring cells and in Figure 10(c) the temperature pattern of this cell alone. The temperature data of the cell neighborhood identify the defected cell having about $10^{\circ} \mathrm{C}$ higher temperature than the nearby cells. The temperature distribution of the defected cell alone (Figure 10(c)) reveals the existence of a large hot spot and hot area in the middle of the cell area. The highest temperature at the hot spot was $47^{\circ} \mathrm{C}$ due to the low irradiation $550 \mathrm{~W} / \mathrm{m}^{2}$ at the time of the experiment, while ambient temperature was $17^{\circ} \mathrm{C}$. The relative temperature differences compared to the remaining part of the cell can be observed.

\section{I-V Curve Analysis}

In order to investigate whether the thermographic information identifying the source of degradation in a PV module correlates with its electrical performance, a series of $I$ $V$ experiments were carried out with the SIEMENS M55 module of Figure 4(a). The $I-V$ curve of the PV module was obtained using the $I-V$ curve analyser. The $I-V$ curve was obtained for a series of shading configurations: with all cells of the module unshaded; with the severely browned cell shaded by $100 \%$ using a black carton; with each one of the three strings of the module successively shaded (all 12 cells) by $100 \%$. This was done in order to determine which string of cells contributed to the deterioration observed in PV performance. It should be noted that each string has 12 cells and the three strings are connected in series. The module has two bypass diodes connected so that the first diode bypasses the first and second strings and the second diode bypasses the second and third strings. Thus, the second string is bypassed by both diodes. When the second string is shaded, the circuit configuration changes so that the first and third strings are now connected in parallel and the total current at the panel output is higher than the current output when all cells are unshaded $[14,15]$. Figure 11 shows the $I-V$ curves obtained under the various configurations. 


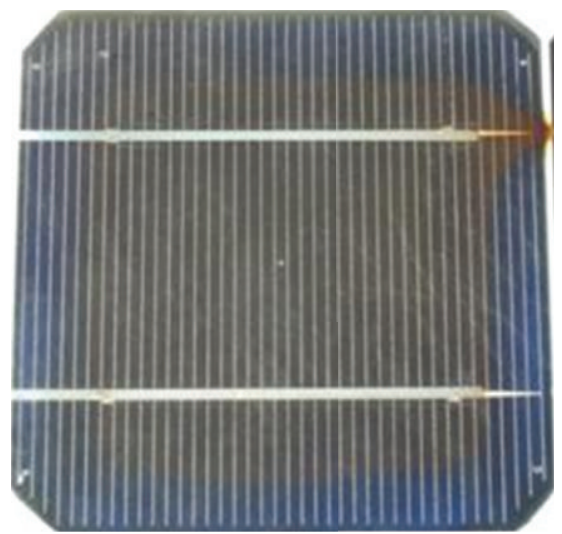

(a)

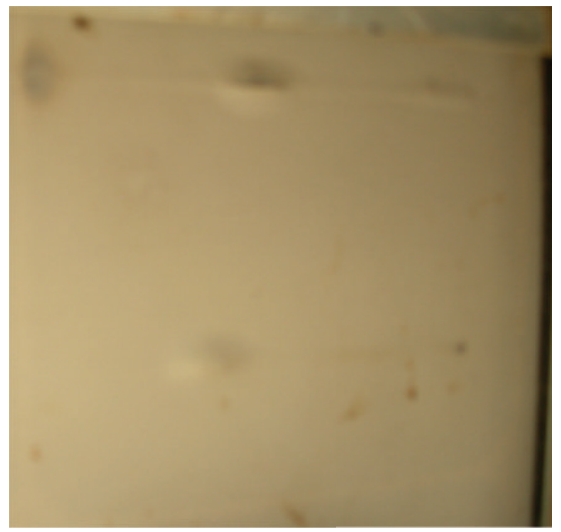

(b)

FIGURE 7: Digital image (a) front and (b) back, of a SIEMENS M55 c-Si cell exhibiting browning, degradation at bus bars and solder bond, and the appearance of blisters at the back sheet tedlar cover.

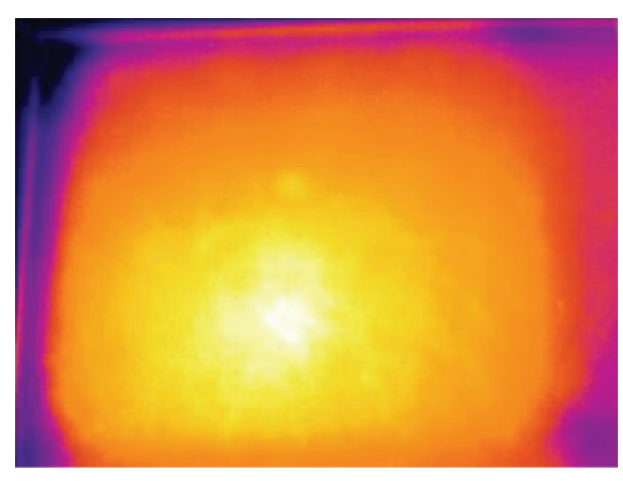

(a)

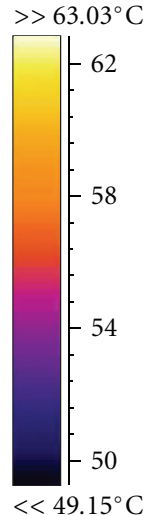

$<<49.15^{\circ} \mathrm{C}$

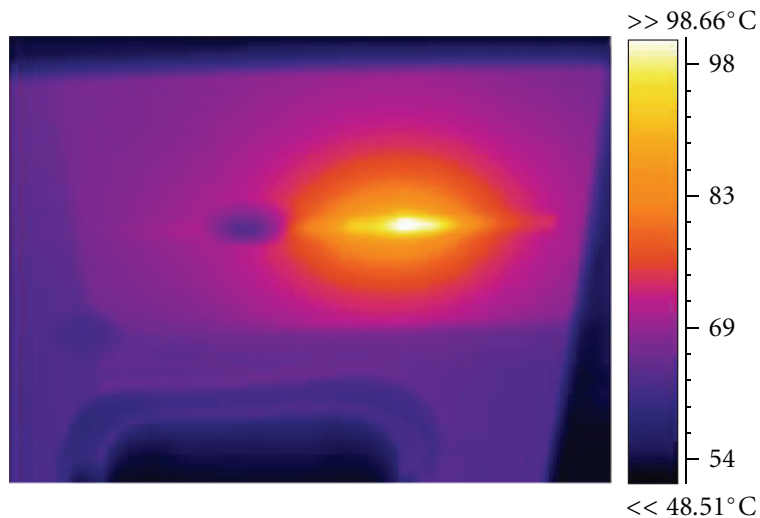

(b)

FIGURE 8: IR image (a) front and (b) back, of the cell displayed in Figure 7, exhibiting a large hot spot area at the front and increased temperature on the bus bar and blister at the back.

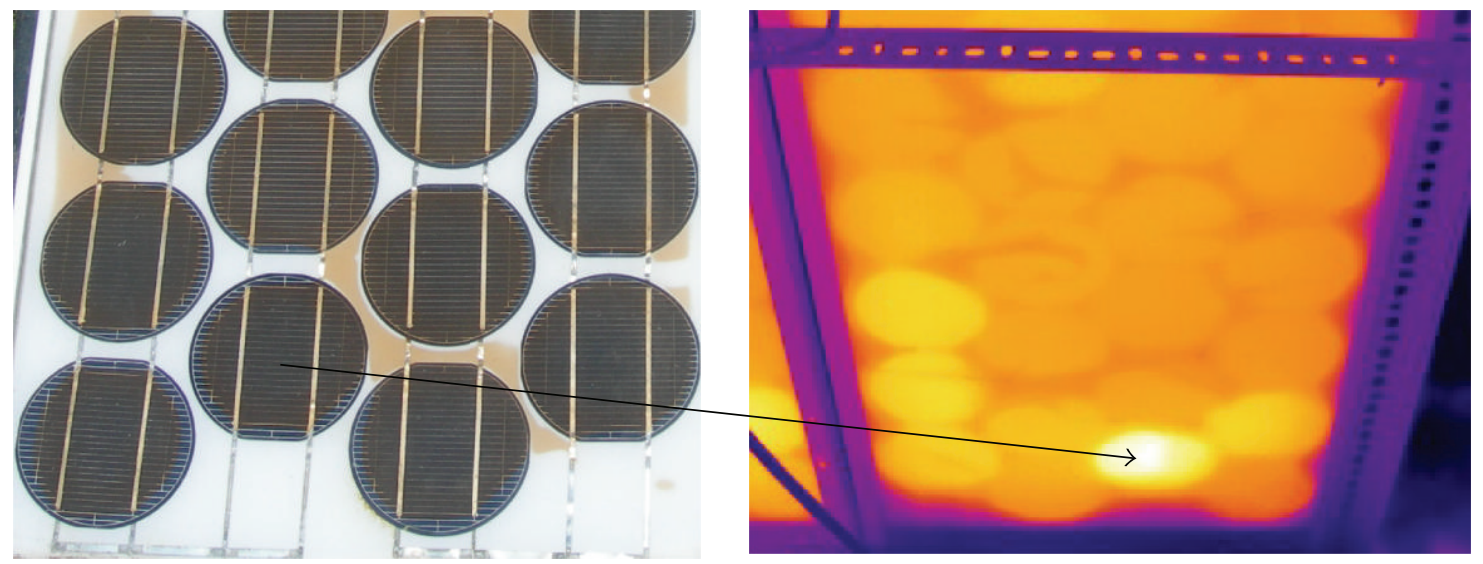

(a) (b)

FIGURE 9: (a) Digital image of the lower part of a BP B 1233 c-Si PV panel; (b) IR image of the back of the panel revealing a hot cell in reverse order as illustrated by the arrow. 


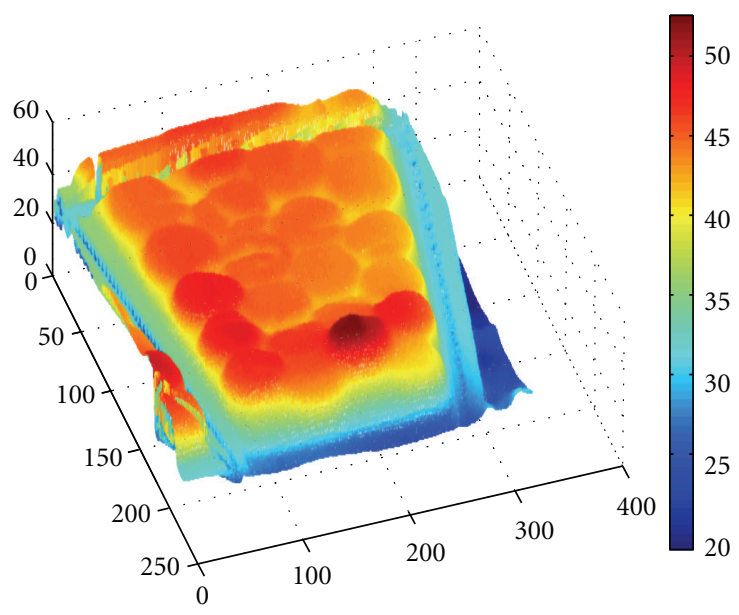

(a)

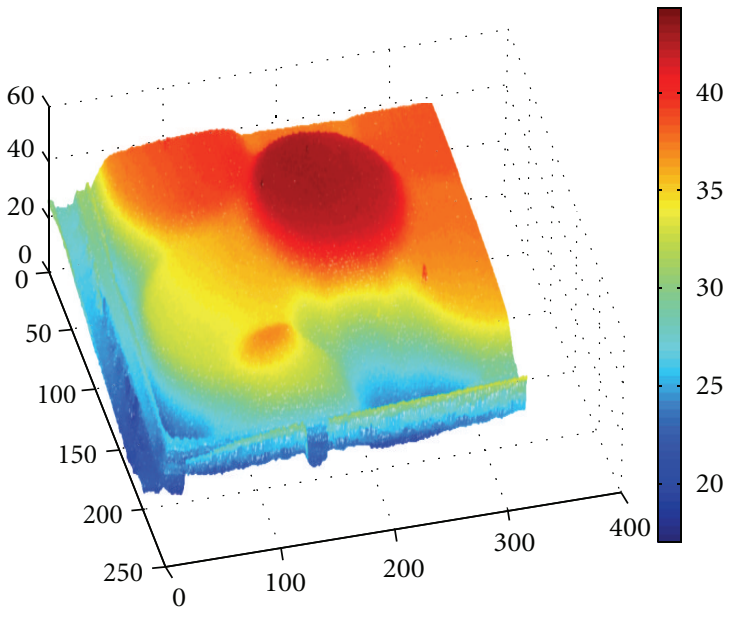

(b)

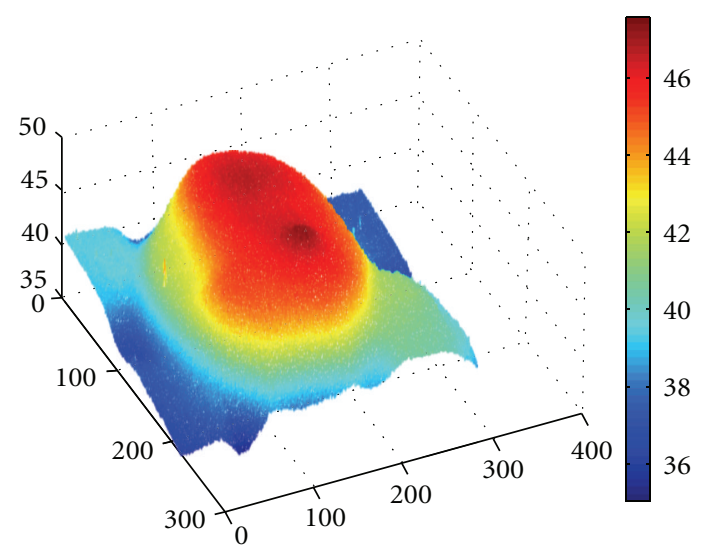

(c)

Figure 10: 3D temperature plot of defected cell and neighboring cells as seen in clockwise order (a) from the back of the panel (in reverse order), (b) the front side lower corner of the panel, and (c) the temperature plot of the defected cell alone revealing a hot spot and hot area.

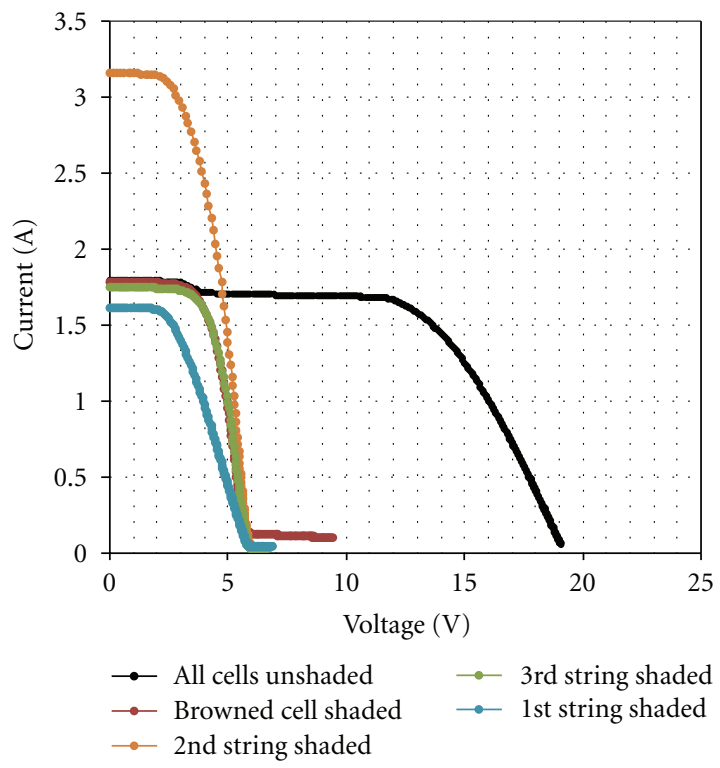

FIGURE 11: $I$ - $V$ curves obtained from the aged SIEMENS M55 PV module under the various configurations. 
The slope of the $I-V$ curve at $V_{\text {oc }}$ indicates the series resistance $R_{s}$, while the slope of the $I-V$ curve at $I_{\mathrm{sc}}$ indicates the shunt resistance $R_{\mathrm{sh}}$ [5]:

$$
\begin{aligned}
& \left.\frac{d V}{d I}\right|_{V=V_{\mathrm{oc}}} \longrightarrow-R_{s}, \\
& \left.\frac{d I}{d V}\right|_{I=I_{\mathrm{sc}}} \longrightarrow-\frac{1}{R_{\mathrm{sh}}} .
\end{aligned}
$$

The $I$ - $V$ curve of a healthy panel would be rather horizontal at $I_{\mathrm{sc}}$ and steep at $V_{\mathrm{oc}}$, indicating high $R_{\mathrm{sh}}$ and low $R_{s}$.

The $I-V$ curve of the PV module in Figure 11, when all cells are unshaded, displays a step-wise decrease, which reveals the existence of deteriorated cell(s). The decreased slope at $V_{\text {oc }}$ proves the existence of a high parasitic series resistance $R_{s}$. On the other hand, the small slope at $I_{\mathrm{sc}}$ indicates high $R_{\mathrm{sh}}$ and therefore a small parasitic shunt resistance. Parasitic shunt resistances arise from high conductivity paths (shunts) in or at the edges of the cell [8], while series resistances arise from contact resistance, bus bar resistance, and fingers [14]. Thus, the $I-V$ curve of the PV module shows that the deterioration in PV performance is mainly due to high resistance at the cell bus bars and contacts.

Due to the connection of the diodes earlier explained, when the first string was entirely shaded, the PV module operated through the cells of the third string. The $I-V$ curve obtained under this configuration (see Figure 11) displays an increased $R_{s}$ illustrated by the decreased slope at $V_{\mathrm{oc}}$. This indicates the existence of a high parasitic resistance in the third string. On the other hand, for the configurations whereby the browned cell was shaded or the third string was entirely shaded, which means that the PV module operated through the cells of the first string, the $I_{\mathrm{sc}}$ remains as high as the initial $I-V$ of the module and the slope at $V_{\text {oc }}$ is now steep indicating a significantly smaller series resistance. Thus, the location of the increased parasitic series resistance is the browned cell located in the third string, as identified by the thermography, which detected in this severely browned cell an increased bus bar resistance due to the high temperature observed at the hot spots located on both bus bars (see Figures 4 and 5).

An indication of the overall PV module performance degradation may be shown through the reduced $P_{m}=$ $47.7 \mathrm{~W}$ and $\mathrm{FF}=61.7 \%$ when converted to standard test conditions (STC). The reduction of $P_{m}$ from the nominal $53 \mathrm{~W}$ value, $\delta P_{m} / P_{m}$, is $10 \%$. It should be noted that a small deviation in the measured power losses may be observed due to spectral variations and sky conditions. While the reduction is obvious and significant, considering the 18 years of field operation of the PV panel, the technology used at the time of production, the optical and electrical degradation which it exhibits, it may be said that the degradation is smaller than expected.

\section{Digital Image Processing}

Visual inspection of PV cells and modules may reveal many optical and electrical defects. As a correlation has been observed between optical degradation and current loss $[4,7]$, which was also shown in this paper, the ability to automatically detect optical degradation through EVA discoloration would bring major improvements in the remote monitoring of the operational health of PV systems and the identification of early signs of degradation. The human eye can easily detect EVA discoloration in PV cells and generally distinguish between largely different degrees of discoloration. An algorithm has been developed in this study to automatically detect optical degradation in PV cells through processing of the digital image alone, in a way closely related to human perception.

The algorithm developed first converts the RGB image of the cell to the HSV (hue, saturation, value) color space. The HSV color model belongs to a group of similar hue-oriented color models (HSI, HSV, HSL) which correspond more closely to the human perception and interpretation of color. These models share the same attribute for hue and differ in terms of their definition of saturation and of intensity/ value/lightness. The HSV coordinate system is cylindrical, and the $\mathrm{H}, \mathrm{S}$, and $\mathrm{V}$ components can be derived from the $\mathrm{R}$, $\mathrm{G}$, and $\mathrm{B}$ components through the following equations [16]. Note that in the equations RGB values are normalized to the range $[0,1]$, and $\mathrm{H}$ needs to be normalized to the range $[0,1]$ by dividing by 360 :

$$
\begin{gathered}
\mathrm{H}= \begin{cases}\theta & \text { if } \mathrm{B} \leq \mathrm{G}, \\
360-\theta & \text { if } \mathrm{B}>\mathrm{G},\end{cases} \\
\text { with } \theta=\cos ^{-1}\left\{\frac{1 / 2(\mathrm{R}-\mathrm{G})+(\mathrm{R}-\mathrm{B})}{\sqrt{(\mathrm{R}-\mathrm{G})^{2}+(\mathrm{R}-\mathrm{B})(\mathrm{G}-\mathrm{B})}}\right\}, \\
S=\frac{\max (\mathrm{R}, \mathrm{G}, \mathrm{B})-\min (\mathrm{R}, \mathrm{G}, \mathrm{B})}{\max (\mathrm{R}, \mathrm{G}, \mathrm{B})}, \\
V=\max (\mathrm{R}, \mathrm{G}, \mathrm{B}) .
\end{gathered}
$$

Segmentation is then carried out in HSV color space based primarily on hue, which is the only component carrying color information. The saturation component is used to mask out regions for which hue is undefined, and the value component is used to further detect different tones of color in regions specified by hue-in order to detect different strengths of browning effect. The segmentation results are presented via a pseudocolor image produced based on the following. Hue in the range of $\left[180^{\circ}, 300^{\circ}\right)$ corresponds to blue colors and is represented with a blue color in the pseudocolor image, identifying the unaffected area of the cell. Hue in the range of $\left[300^{\circ}, 360^{\circ}\right]$ and $\left[0^{\circ}, 60^{\circ}\right]$ corresponds to red and golden colors and is represented by red in the pseudocolor image, which identifies the yellowing and browning in discolored cell areas. Depending on the value component and with respect to different hues, a greater value of $V$ is represented in brighter color (red or blue) in the pseudocolor image while a smaller value of $V$ in darker color, 


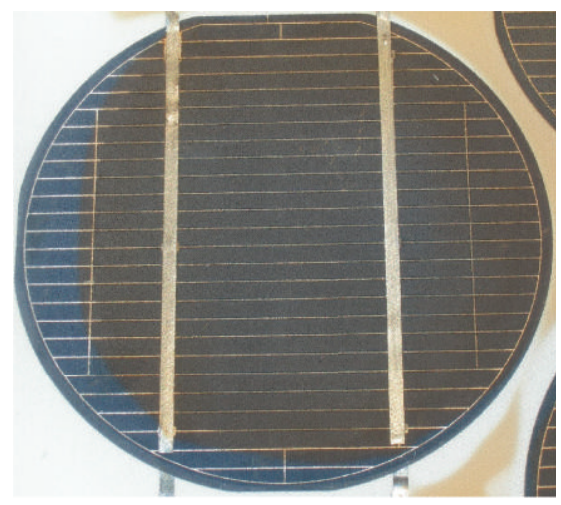

(a)

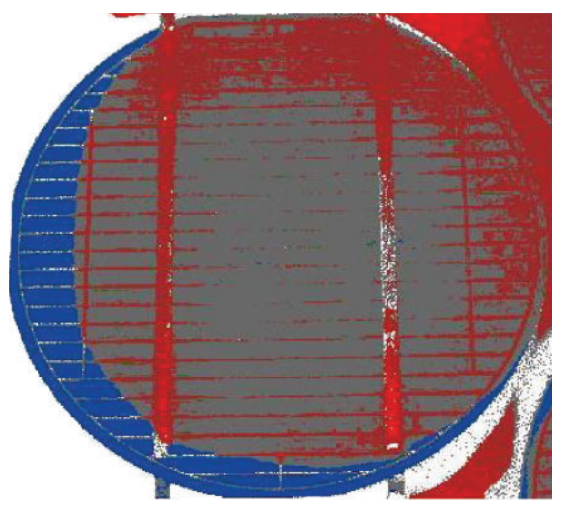

(b)

FIGURE 12: (a) Original digital image of a c-Si BP B1233 cell, (b) respective pseudocolour image provided by the proposed segmentation algorithm.

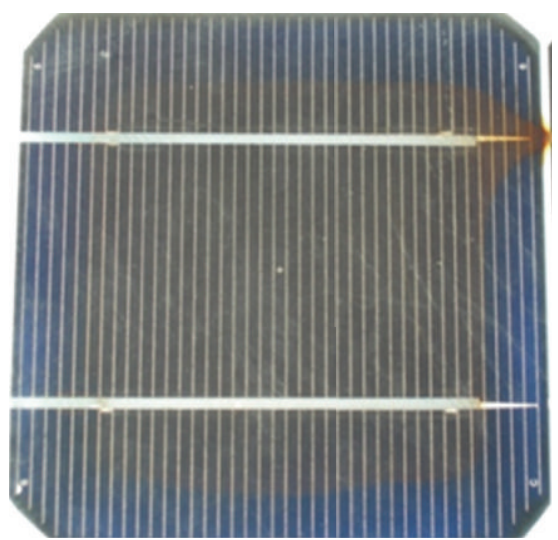

(a)

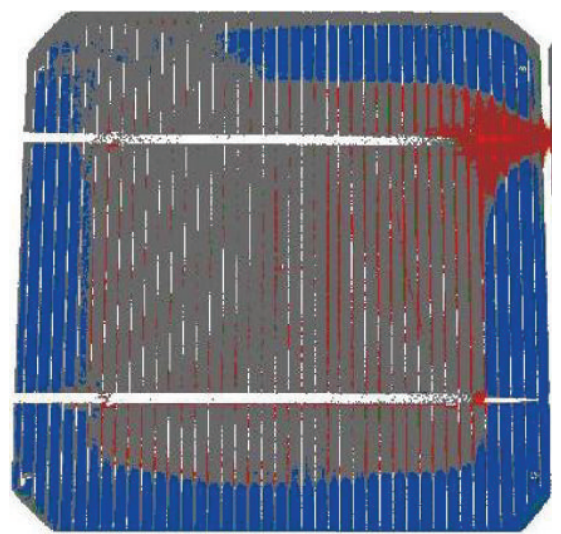

(b)

FIGURE 13: (a) Original digital image of a c-Si SIEMENS M55 cell, (b) respective pseudocolour image provided by the proposed segmentation algorithm.

signifying different levels of brightness in the color. Values of $V$ near 0 are represented with black. Values of $S$ near 0 and $V$ near 1 are represented with white in the pseudocolor image and distinguish the street regions between the cells. For saturation 0 the value of hue is irrelevant. Saturation near 0 , signifying ambiguous grey-ish colors, often evident in discolored parts of the cell, is represented in gray color in the pseudocolor image.

Figures 12(a) and 12(b) show, respectively, the original digital image of an aged c-Si cell from the BP B 1233 PV module, and the pseudocolor image produced by the segmentation algorithm. It may be observed in the pseudocolor image that the undamaged part of the cell has been accurately detected, and the nonbrowned part of the street surface around the cell. Furthermore, the browning has been accurately detected on all affected areas, which is shown in red and dark red color in the pseudocolor image. Also, areas exhibiting different severity of browning appear in grey color in the pseudocolor image. The browning which appears on the bus bars and fingers has also been accurately detected. Figure 13(b) displays the resulting pseudocolor image for a browned c-Si cell from a SIEMENS M55 module (Figure 13(a)). It is evident that the pseudocolor image produced has accurately detected the undamaged and damaged parts of the cell. The browning which appears on both bus bars and soldering bond is clearly detected and appears in red in the pseudocolor image. The small browning at the lower bus bar, which could have been passed unnoticed during a visual inspection, has been correctly identified and appears in red in the pseudocolor image.

The identified discoloured part of the cell is also measured in terms of percentage area of coverage with respect to the true area of the cell, and in terms of the different tones of colour in order to identify the severity of browning detected. An extended analysis of this algorithm will be presented in a separate study.

\section{Discussion}

Optical and electrical defects in field-aged PV modules of 18-22 years of operation have been identified and analysed through visual inspection, digital image processing, IR thermography, and $I-V$ curve analysis. The SIEMENS M55 
modules exhibited in certain cells severe optical degradation which was induced by external field factors in the past, while the BP B 1233 module exhibited severe natural EVA discolouration. PV cells exhibiting severe EVA discoloration were identified through visual inspection, and the IR image of the PV panels also confirmed temperature degradation defects in these discolored cells. Severely discolored cells of the M55 module exhibited degradation defects mainly on the bus bars of the cell, increasing cell temperature and, further, increasing the series resistance of the cell. This in turn causes mismatch effects and reduces the power output of the module as seen in the $I-V$ curve analysis performed. The temperature measured at the hot spots reached temperatures above $95^{\circ} \mathrm{C}$ for the experiments carried out during September 2011, which is detrimental for the operational health of the cell. In the most severe cases examined, hot spots experienced temperature increase $\delta T_{c} / T_{c}$ by $50 \%-80 \%$ compared to the temperature of the nearby cells. Cells including these hot spots experienced an average temperature increase in the entire cell by $20-50 \%$ compared to the temperatures of the nearby cells. Milder hot areas due to junction box effects exhibited temperature increase by about $15 \%$ compared to the temperature of the nearby cells. Hot spots in the IR image of the BP cell captured during April exhibited also a temperature increase by about $18 \%$ compared to the temperature of nearby cells. For measurements under higher ambient temperature and higher solar radiation, this relative temperature increase at the hot spots and within the cell is expected to be higher mainly due to the Joule effect $I^{2} R_{s}$.

Due to the overall conductance of the PV module front cover, temperature propagation appears around the area of the hot spot. It was shown that the IR image at the back of the panel exhibited more precisely the temperature topography assisting in the identification of the exact location of the hot spots. In addition, higher temperatures by about $10^{\circ} \mathrm{C}$ were measured at the back side of the panels compared to temperatures measured at the front.

IR images were captured at different seasons, and the identification of the hot spots was possible even for cases when solar radiation was much lower than the maximum range observed during summer. This highlights the appropriateness and flexibility of the IR thermography as a method for defect detection. Nevertheless, the severity of the defect needs to be considered also under the high solar radiation conditions that prevail at the site of the PV installation for an indication of the maximum temperatures that may be observed and may be accounted responsible for permanently increasing deterioration of the operational health of the cells and modules. On the other hand, identification of discolored cells, hot spots, and defected areas can be reliably performed even during colder months of the year.

Via means of an $I-V$ curve analyser, the $I-V$ curves obtained through a series of experiments on one of the modules led to a correlation between the results of the visual inspection, thermography, and the $I-V$ curve characteristics. The hot spots on the bus bars and solder bond identified through the IR thermography was verified by the $I-V$ curve characteristics showing increased parasitic series resistance when operating with the severely discolored cell, identifying this cell as the source of electrical performance degradation for the module.

The algorithm developed for the automatic detection of EVA discoloration in PV cells via digital image processing gave reliable results identifying correctly the discolored cell area and the healthy part of the cell. The percentage area of coverage of the discoloration with respect to the true area of the cell and the identification of different tones of color gives estimates of the severity of browning detected. The ability to easily detect optical degradation is of high importance for the inspection and monitoring of the operational health of PV modules. This could be applied in the detection of EVA discoloration in existing PV installations via means of a single digital picture, or in the automatic monitoring and remote inspection of PV systems.

\section{Conclusions}

This paper has presented and analysed optical and electrical degradation effects in modules operating under field conditions already for 18-22 years. Certain modules or cells had experienced heavily induced degradation by external field factors, while others exhibited signs of severe EVA discoloration due to natural aging. The degree of EVA discoloration observed differed between cells and modules with some cells exhibiting severe signs of discoloration which affected the bus bars and contacts of the cells. The type of optical degradation also differed among modules, with most experiencing EVA discoloration and a few exhibiting a higher degree of delamination of the encapsulant. The naturally aged BP module did not exhibit the severe degradation of bus bars and contacts, which was observed in the cells of the M55 modules subjected to the induced aging by the external factors.

The optical degradation was detected through visual inspection and through IR thermography, which reliably identified hot spots and hot areas, leading to increased series resistance in the cells and causing mismatch effects. Results of the IR thermography were also verified by the $I-V$ curve characteristics showing increased parasitic series resistance when operating with the severely discolored cell, identifying this cell as the source of electrical performance degradation for the module. The IR thermography proved a reliable and accurate tool for the diagnosis of degradation defects, both optical and electrical, in PV cells and, furthermore, for the identification of the precise location and the severity of these faults. The relative temperature differences measured within the cell or between neighboring cells may further assist in the diagnosis of early signs of degradation. This is important as degradation is observed to advance in an increasing rate.

Finally, an algorithm was developed to automatically detect EVA discoloration in cells through digital image processing in a way closely imitating human perception of color. The algorithm gives an accurate identification of the healthy and discolored part of the cell and presents the result in pseudocolor image. Furthermore, it identifies different degrees of severity of discoloration and gives an estimate of the percentage area coverage of the discoloration. This novel 
approach brings several advantages in the area of automatic defect diagnosis for remote inspection and monitoring of PV cell and module condition. The latter is particularly important for the early diagnosis of faults, assisting in prolonging the operational lifetime of the system.

\section{Acknowledgments}

The project is cofunded by the European Union-European Regional Development Fund and National Resources (NSRF 2007-2013). The author would like to express her appreciation for the funding received. The author would also like to express her gratitude to Professor S. Kaplanis, Head of the R.E.S. Laboratory of T.E.I. of Patras and project coordinator, for his valuable input.

\section{References}

[1] A. Goetzberger, C. Hebling, and H. W. Schock, "Photovoltaic materials, history, status and outlook," Materials Science and Engineering R, vol. 40, no. 1, pp. 1-46, 2003.

[2] R. W. Birkmire, "Compound polycrystalline solar cells: recent progress and Y2K perspective," Solar Energy Materials and Solar Cells, vol. 65, no. 1, pp. 17-28, 2001.

[3] S. Nann and K. Emery, "Spectral effects on PV-device rating," Solar Energy Materials and Solar Cells, vol. 27, no. 3, pp. 189216, 1992.

[4] A. Parretta, M. Bombace, G. Graditi, and R. Schioppo, "Optical degradation of long-term, field-aged c-Si photovoltaic modules," Solar Energy Materials and Solar Cells, vol. 86, no. 3, pp. 349-364, 2005.

[5] S. Kaplanis and E. Kaplani, "Energy performance and degradation over 20 years performance of bp c-Si PV modules," Simulation Modelling Practice and Theory, vol. 19, no. 4, pp. 1201-1211, 2011.

[6] A. W. Czanderna and F. J. Pern, "Encapsulation of PV modules using ethylene vinyl acetate copolymer as a pottant: a critical review," Solar Energy Materials and Solar Cells, vol. 43, no. 2, pp. 101-181, 1996.

[7] D. Chianese, A. Realini, N. Cereghetti et al., "Analysis of weathered c-si pv modules," in Proceddings of the 3rd World Conference on Photovoltaic Energy Conversion, pp. 2922-2926, Osaka, Japan, May 2003.

[8] C. Radue and E. E. van Dyk, "A comparison of degradation in three amorphous silicon PV module technologies," Solar Energy Materials and Solar Cells, vol. 94, no. 3, pp. 617-622, 2010.

[9] M. Simon and E. L. Meyer, "Detection and analysis of hot-spot formation in solar cells," Solar Energy Materials and Solar Cells, vol. 94, no. 2, pp. 106-113, 2010.

[10] A. Skoczek, T. Sample, and E. D. Dunlop, "The results of performance measurements of field-aged crystalline silicon photovoltaic modules," Progress in Photovoltaics: Research and Applications, vol. 17, no. 4, pp. 227-240, 2009.

[11] S. Vergura and O. Falcone, "Filtering and processing IR images of PV modules," in Proceedings of the International Conference on Renewable Energies and Power Quality (ICREPQ' 11), Las Palmas, Spain, April 2011.

[12] P. N. Botsaris and J. A. Tsanakas, "Infrared thermography as an estimator technique of a photovoltaic module performance via operating temperature measurements," in Proceedings of the 10th ECNDT Conference, Moscow, Russia, June 2010.
[13] D. L. King, J. A. Kratochvil, and M. A. Quintana, “Applications for infrared imaging equipment in photovoltaic cell, module, and system testing," in Proceedings of the 28th IEEE Conference Record of the Photovoltaic Specialists Conference, pp. 14871490, Anchorage, Alaska, USA, September 2000.

[14] S. Silvestre, A. Boronat, and A. Chouder, "Study of bypass diodes configuration on PV modules," Applied Energy, vol. 86, no. 9, pp. 1632-1640, 2009.

[15] Y. J. Wang and P. C. Hsu, "Analysis of partially shaded pv modules using piecewise linear parallel branches model," Proceedings of World Academy of Science, Engineering and Technology, vol. 60, pp. 783-789, 2009.

[16] K. N. Plataniotis and A. N. Venetsanopoulos, Color Image Processing and Applications, Springer, 2000. 


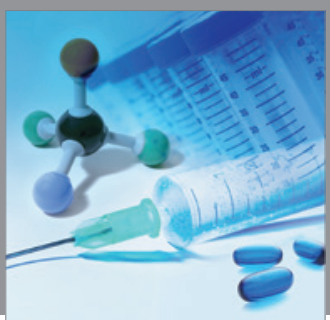

International Journal of

Medicinal Chemistry

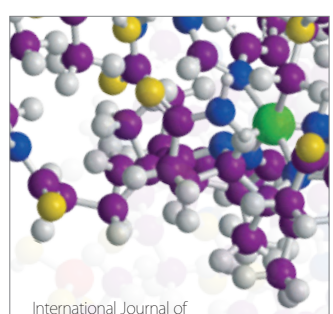

Carbohydrate Chemistry

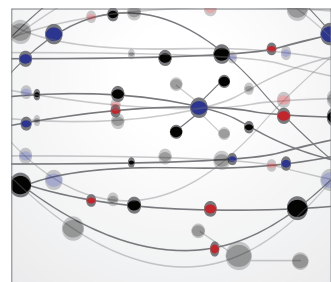

The Scientific World Journal
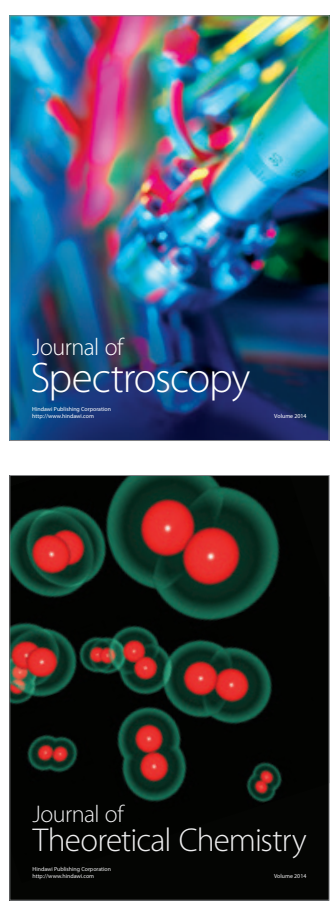
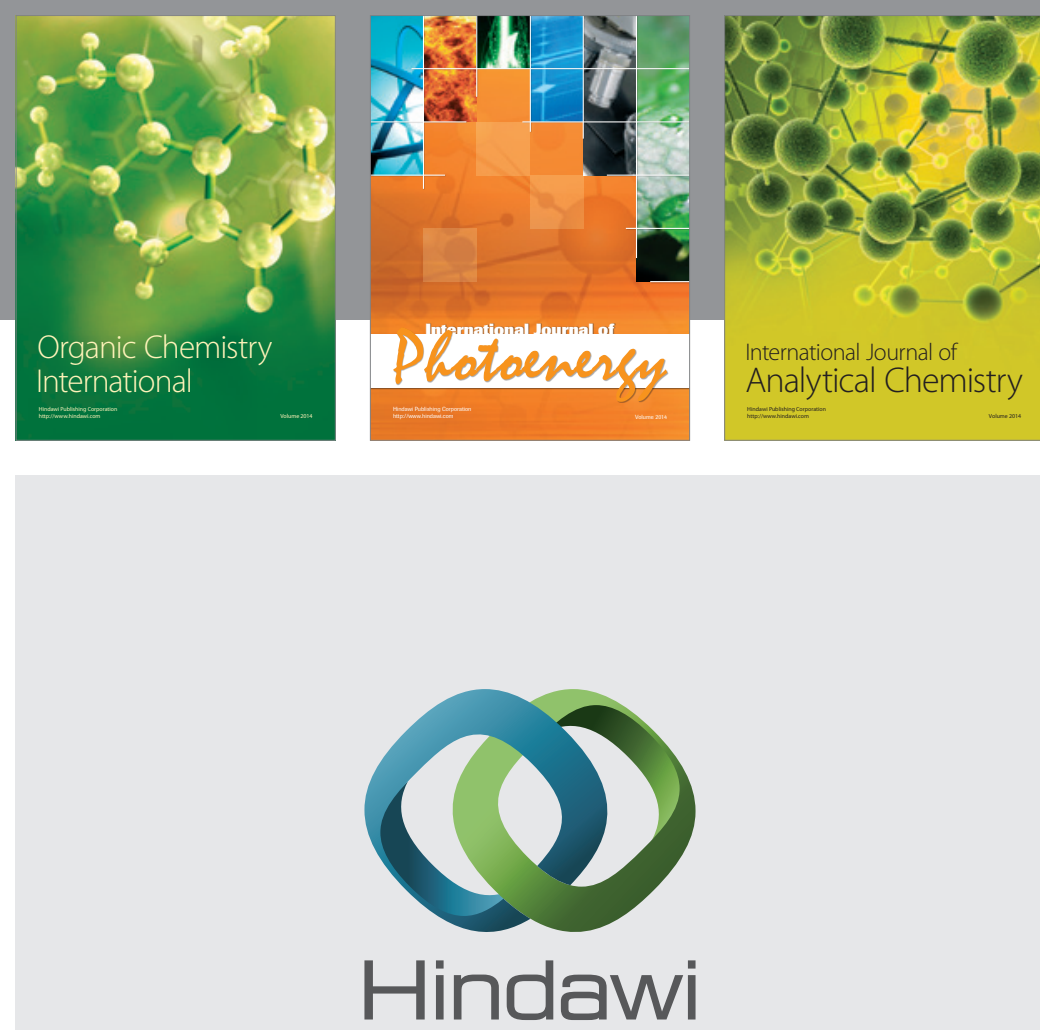

Submit your manuscripts at

http://www.hindawi.com
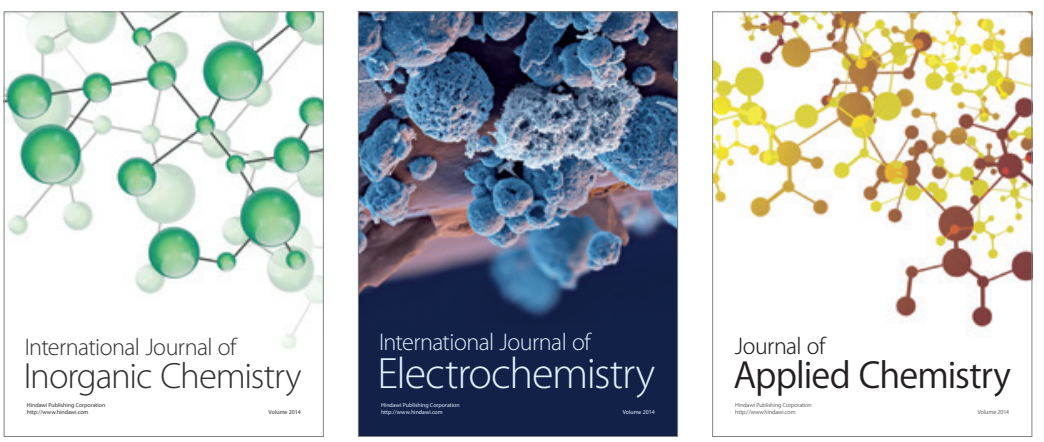

Journal of

Applied Chemistry
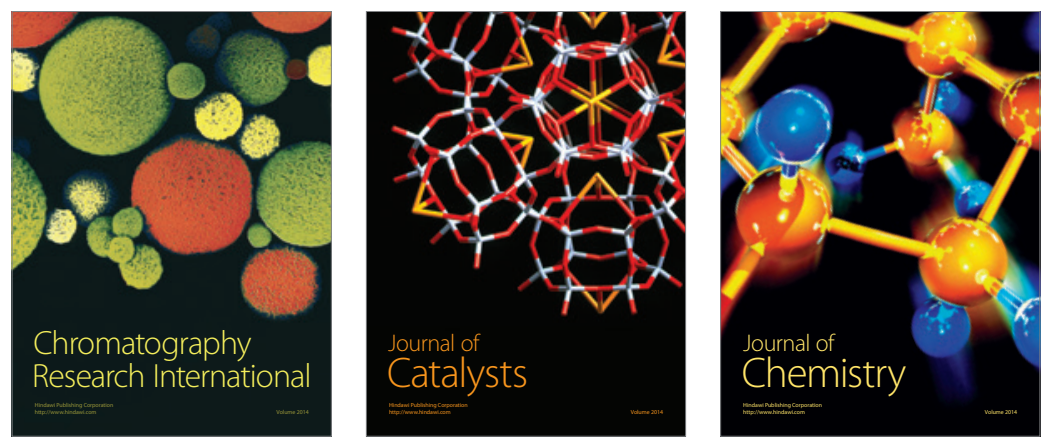
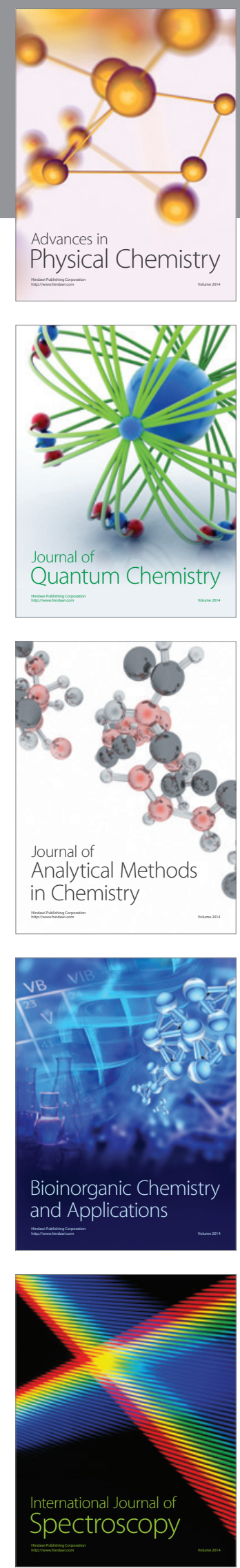